\title{
Psychiatric Inpatients from an Urban Community, I968-72
}

\author{
T. FRYERS
}

British Medical fournal, 1973, 2, 76-80

\section{Summary}

The psychiatric inpatient population from Salford was analysed in five successive annual censuses, from 1 January 1968 to 1 January 1972. Short-stay and mediumstay patients (under one year) remained constant. Longstay patients reduced only slowly, and the length of stay increased. Over 200 patients $(60 \%)$ had been in for 20 years or more at 1 January 1972. Analysis showed that the 1968 long-stay cohort diminished by 122 patients $(29 \%)$ in four years, while 54 new long-stay patients accumulated. There seems little prospect of emptying large psychiatric hospitals of their long-stay population.

\section{Introduction}

In spite of the emphasis placed on domiciliary and local care in psychiatry over the past decade or so, the size, state, and future of our mental hospitals has continued to excite much interest and provoke much comment. Since the mistaken optimism of the late 1950s, when Tooth and Brooke (1961) predicted a rapid decline in hospital populations, their early and later critics (Baldwin, 1968) have been vindicated and many less hopeful forecasts have gained currency. Having reached the 1970s we can examine what beds we still use, and must recognize that the problems remain. This paper represents one such examination based on the psychiatric case register in Salford, a predominantly working-class borough of some 130,000 persons within the Greater Manchester conurbation in the north-west of England.

\section{Methods and Results}

The Salford register records all contacts with formal psychiatric and mental health agencies of people with Salford addresses. It follows a similar organizational pattern to the Camberwell register (Wing et al., 1968; Wing and Hailey, 1972). The initial census of people currently receiving any form of psychiatric care was taken at 1 January 1968 and was reported by Fryers et al. (1970). Some of this census data was incorporated in a report by Susser et al. (1970) and related to an earlier Salford register described by Adelstein et al. (1968).

\section{BACKGROUND}

The present study is concerned only with adult inpatients, and very largely with long-stay inpatients, from 1 January 1968 to 1 January 1972, a period of four years representing five successive annual censuses. Patients from Salford, with very few exceptions, are at present admitted either to one general hospital psychiatric unit within the city or one unit of a large mental hospital close to the city boundaries. On the other hand, longer-stay patients \footnotetext{
Department of Social and Preventive Medicine, University of
Manchester, Manchester M13 0JJ

T. FRYERS, M.B., D.P.H., Lecturer
}

admitted over the past 65 years are scattered throughout the north-west of England in nine different hospitals, though about two-thirds of them are in only two hospitals. Long-stay patients tend to attract little active psychiatry and little attention from community mental health services. Therefore, up to now, few have had realistic chances of discharge and most remain in hospital until they die. Currently in Salford as elsewhere the future of the long-stay patients is very actively under discussion. Their need for continued stay in hospital or for active treatment is doubted, and alternative forms of care are being proposed. It is necessary, therefore, to be very clear about how many people are affected, who they are, and what they are like.

To place the inpatient data in context, table I shows some aspects of the wider service the hospitals provide. Admissions are currently about 550-600 a year, 5\% of which are prolonged beyond one year, a similar figure to the Camberwell Study (Hailey, 1971).

TABLE I-Distribution of Psychiatric Admissions during 1968-70 Compared with Rate of Outpatient Management 1970 (Adults)*

\begin{tabular}{|c|c|c|c|}
\hline \multirow[b]{2}{*}{ Total admissions: } & 1968 & 1969 & 1970 \\
\hline & 572 & 542 & 593 \\
\hline 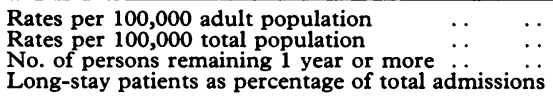 & $\begin{array}{r}545 \\
408 \\
28 \\
4 \cdot 9\end{array}$ & $\begin{array}{r}521 \\
393 \\
28 \\
5 \cdot 2\end{array}$ & $\begin{array}{r}581 \\
436 \\
31 \\
5 \cdot 2\end{array}$ \\
\hline
\end{tabular}

*In 1970959 adult outpatients made a total of 2,298 contacts.

\section{PREVALENCE}

The overall inpatient day prevalence in five successive years by sex, age, and length of stay is given in table II. The prevalence at 1 January 1972 by sex, diagnosis, and length of stay is shown in table III. Long-stay is defined as a continuous period of residence of at least one year, and this is now to be preferred to a two-year period since so few patients remain longer than a few months, and after one year the risk of remaining very much longer is high. (Shepherd, 1957; Brown, 1960; Hassall et al., 1965; Hailey, 1971.)

The numbers of short-stay (0-60 days) and medium-stay patients (61-364 days) fluctuated, but were roughly equal and together showed a slight increase (77 to 84 ) over the five censuses. About two-thirds were women. About a fifth to a quarter of short-stay patients and a third to a half of mediumstay patients, almost all women, were aged 65 years or over. These figures represent the actual bed use of Salford patients at a time when there was no overt shortage of beds. They cannot tell us about "need," a subtle and complex thing, but they do reflect "demand" within the present social and psychiatric circumstances. They do not pronounce on the desirability of admission or the possibility of alternative forms of care; they merely reflect the common practice of and options open to psychiatrists operating the service. The rate for short-stay and medium-stay beds together is roughly $60 / 100,000$ of the total population.

The long-stay patient total diminished over four years by 68 , from 417 to 349 , an average fall of $4.4 \%$ and a total of $16.3 \%$. The number of patients 65 years and over fell only $10 \%$, and the number of women 65 and over fell by only $5 \cdot 6 \%$. In general, the long-stay population contained slightly more women than 
TABLE II-Salford Inpatients 1968-72 by Age, Sex, and Length of Stay (Figures adjusted for Ageing)

\begin{tabular}{|c|c|c|c|c|c|c|c|c|c|c|c|c|c|c|c|c|}
\hline \multirow[b]{3}{*}{ Length of Stay } & \multirow[b]{3}{*}{ Age } & \multicolumn{15}{|c|}{ Census Year (1 January) } \\
\hline & & \multicolumn{3}{|c|}{1968} & \multicolumn{3}{|c|}{1969} & \multicolumn{3}{|c|}{1970} & \multicolumn{3}{|c|}{1971} & \multicolumn{3}{|c|}{1972} \\
\hline & & M. & F. & Total & M. & F. & Total & M. & F. & Total & M. & F. & Total & M. & F. & Total \\
\hline Long stay (1 year or more) & $\begin{array}{l}<65 \\
\geqslant 65\end{array}$ & $\begin{array}{r}147 \\
55\end{array}$ & $\begin{array}{l}108 \\
107\end{array}$ & $\begin{array}{l}255 \\
162\end{array}$ & $\begin{array}{r}134 \\
51\end{array}$ & $\begin{array}{l}102 \\
106\end{array}$ & $\begin{array}{l}236 \\
157\end{array}$ & $\begin{array}{r}130 \\
48\end{array}$ & $\begin{array}{r}98 \\
101\end{array}$ & $\begin{array}{l}228 \\
149\end{array}$ & $\begin{array}{r}123 \\
44\end{array}$ & $\begin{array}{l}94 \\
96\end{array}$ & $\begin{array}{l}217 \\
140\end{array}$ & $\begin{array}{r}119 \\
45\end{array}$ & $\begin{array}{r}84 \\
101\end{array}$ & $\begin{array}{l}203 \\
146\end{array}$ \\
\hline Total & & 202 & 215 & 417 & 185 & 208 & 393 & 178 & 199 & 377 & 167 & 190 & 357 & 164 & 185 & 349 \\
\hline Medium stay (61-364 days) & $\begin{array}{l}<65 \\
\geqslant 65\end{array}$ & $\begin{array}{l}8 \\
1\end{array}$ & $\begin{array}{r}18 \\
7\end{array}$ & $\begin{array}{r}26 \\
8\end{array}$ & 20 & $\begin{array}{r}8 \\
12\end{array}$ & $\begin{array}{l}28 \\
12\end{array}$ & $\begin{array}{l}8 \\
1\end{array}$ & $\begin{array}{r}13 \\
8\end{array}$ & 21 & $\begin{array}{r}10 \\
2\end{array}$ & $\begin{array}{l}20 \\
12\end{array}$ & $\begin{array}{l}30 \\
14\end{array}$ & $\begin{array}{r}12 \\
1\end{array}$ & $\begin{array}{l}19 \\
10\end{array}$ & $\begin{array}{l}31 \\
11\end{array}$ \\
\hline Total & & 9 & 25 & 34 & 20 & 20 & 40 & 9 & 21 & 30 & 12 & 32 & 44 & 13 & 29 & 42 \\
\hline Short stay (0-60 days) .. & $\begin{array}{l}<65 \\
\geqslant 65\end{array}$ & 14 & $\begin{array}{r}22 \\
7\end{array}$ & $\begin{array}{r}36 \\
7\end{array}$ & $\frac{9}{-}$ & $\begin{array}{r}23 \\
4\end{array}$ & $\begin{array}{r}32 \\
4\end{array}$ & $\begin{array}{r}14 \\
3\end{array}$ & $\begin{array}{r}22 \\
6\end{array}$ & $\begin{array}{r}36 \\
9\end{array}$ & $\begin{array}{r}14 \\
3\end{array}$ & $\begin{array}{r}16 \\
6\end{array}$ & $\begin{array}{r}30 \\
9\end{array}$ & $\begin{array}{r}15 \\
1\end{array}$ & $\begin{array}{r}19 \\
7\end{array}$ & $\begin{array}{r}34 \\
8\end{array}$ \\
\hline Total & & 14 & 29 & 43 & 9 & 27 & 36 & 17 & 28 & 45 & 17 & 22 & 39 & 16 & 26 & 42 \\
\hline All inpatients $\quad .$. & $\begin{array}{l}\leqslant 65 \\
\geqslant 65\end{array}$ & $\begin{array}{r}169 \\
56 \\
\end{array}$ & $\begin{array}{l}148 \\
121 \\
\end{array}$ & $\begin{array}{l}317 \\
177 \\
\end{array}$ & $\begin{array}{r}163 \\
51 \\
\end{array}$ & $\begin{array}{l}133 \\
122\end{array}$ & $\begin{array}{l}296 \\
173 \\
\end{array}$ & $\begin{array}{r}152 \\
52 \\
\end{array}$ & $\begin{array}{l}133 \\
115\end{array}$ & $\begin{array}{l}285 \\
167 \\
\end{array}$ & $\begin{array}{r}147 \\
49 \\
\end{array}$ & $\begin{array}{l}130 \\
114\end{array}$ & $\begin{array}{l}277 \\
163 \\
\end{array}$ & $\begin{array}{r}146 \\
47\end{array}$ & $\begin{array}{l}122 \\
118 \\
\end{array}$ & $\begin{array}{l}268 \\
165\end{array}$ \\
\hline Total & & 225 & 269 & 494 & 214 & 255 & 469 & 204 & 248 & 452 & 196 & 244 & 440 & 193 & 240 & 433 \\
\hline
\end{tabular}

TABLE III-Salford Inpatients at 1 fanuary 1972 by Sex, Diagnosis, and Length of Stay (Figures adjusted for Ageing)

\begin{tabular}{|c|c|c|c|c|c|c|c|c|c|c|c|c|c|c|c|c|c|c|c|}
\hline \multirow{2}{*}{\multicolumn{5}{|c|}{ Length of Stay }} & \multicolumn{3}{|c|}{ Schizophrenia } & \multicolumn{3}{|c|}{ Depression } & \multicolumn{3}{|c|}{ Organic Psychoses } & \multicolumn{3}{|c|}{ Other Diagnoses } & \multicolumn{3}{|c|}{ All Diagnoses } \\
\hline & & & & & M. & F. & Total & M. & F. & Total & M. & F. & Total & M. & F. & Total & M. & F. & Total \\
\hline $\begin{array}{l}\text { Short stay (0-60 days) } \\
\text { Medium stay (61-364 days) }\end{array}$ & $\because$. & 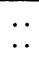 & $\because$ & . & $\begin{array}{l}7 \\
5\end{array}$ & $\begin{array}{l}8 \\
8\end{array}$ & $\begin{array}{l}15 \\
13\end{array}$ & $\underline{4}$ & $\begin{array}{r}10 \\
7\end{array}$ & $\begin{array}{r}14 \\
7\end{array}$ & $\begin{array}{l}1 \\
5\end{array}$ & $\begin{array}{r}4 \\
10\end{array}$ & $\begin{array}{r}5 \\
15\end{array}$ & $\begin{array}{l}4 \\
3\end{array}$ & $\begin{array}{l}4 \\
4\end{array}$ & $\begin{array}{l}8 \\
7\end{array}$ & $\begin{array}{l}16 \\
13\end{array}$ & $\begin{array}{l}26 \\
29\end{array}$ & $\begin{array}{l}42 \\
42\end{array}$ \\
\hline Total < 1 year & & & & & 12 & 16 & 28 & 4 & 17 & 21 & 6 & 14 & 20 & 7 & 8 & 15 & 29 & 55 & 84 \\
\hline Long stay (1 year or more) & . & .. & . & .. & 117 & 101 & 218 & 5 & 17 & 22 & 26 & 43 & 69 & 16 & 24 & 40 & 164 & 185 & 349 \\
\hline Total all patients & & & & & 129 & 117 & 246 & 9 & 34 & 43 & 32 & 57 & 89 & 23 & 32 & 55 & 193 & 240 & 433 \\
\hline
\end{tabular}

TABLE IV-Inpatient Censuses in England and Wales: Comparison of Rates per 100,000 Total Population by Length of Stay

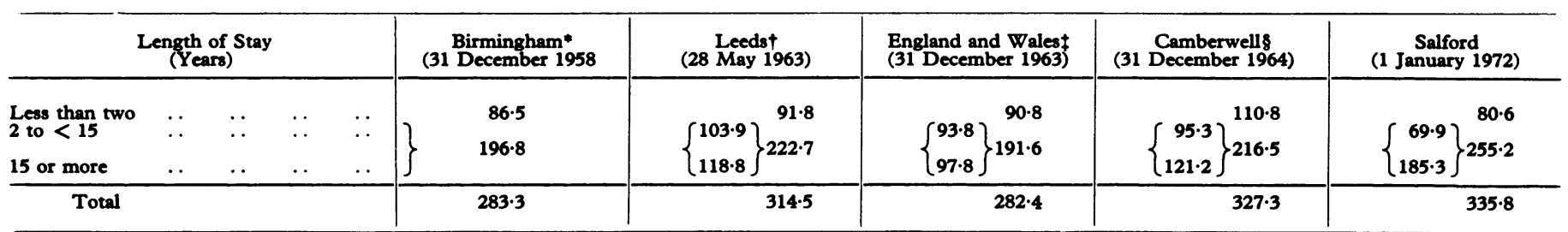

*Cross and Yates, 1961.

+Gore et al., 1964.

\$Hrooke, 1967.

men, about $40 \%$ were aged 65 and over ( $50 \%$ of women), and $40 \%$ had a diagnosis of schizophrenia. Camberwell's long-stay population in 1964 had more old people (49\%) and more schizophrenic patients $(57 \%$ ) (Hailey, 1971). A comparison of inpatient prevalence rates at 1 January 1972 with other censuses is given in table IV (Hailey, 1971). Salford's higher rates are restricted to longer periods of stay. This must at

TABLB V-Comparison of Lengths of Stay of Camberwell (1967 Census) and Salford (1968 and 1972 Censuses) Long-stay Patients Expressed as Percentage of Patients

\begin{tabular}{|c|c|c|c|c|}
\hline \multirow{2}{*}{\multicolumn{2}{|c|}{$\begin{array}{c}\text { Length of Stay } \\
\text { (Years) }\end{array}$}} & \multirow{2}{*}{$\begin{array}{l}\text { Camberwell* } \\
\text { (31 December 1967) }\end{array}$} & \multicolumn{2}{|c|}{ Salford } \\
\hline & & & 1 January 1968 & 1 January 1972 \\
\hline $\begin{array}{r}1 \text { or more } . . \\
5 \text { or more }: . \\
10 \text { or more }: . \\
15 \text { or more }: . \\
20 \text { or more }: . \\
25 \text { or more } \\
30 \text { or more } \\
35 \text { or more } \\
40 \text { or more } \\
45 \text { or more } \\
50 \text { or more }\end{array}$ & $\begin{array}{l}. \\
\because \\
\because\end{array}$ & $\begin{array}{c}100 \\
74 \cdot 9 \\
63.4 \\
51.9 \\
41.0 \\
34.1 \\
17 \cdot 3 \\
5.6\end{array}$ & $\begin{array}{c}100 \\
84.6 \\
73.0 \\
63.9 \\
50.2 \\
38.6 \\
24.6 \\
16.4 \\
8.9 \\
3.6 \\
1.4\end{array}$ & $\begin{array}{c}100 \\
84.6 \\
77.1 \\
68.5 \\
60.2 \\
46.7 \\
34.7 \\
21.8 \\
13.2 \\
6.3 \\
2.0\end{array}$ \\
\hline
\end{tabular}

•Hailey, 1971. least be partly due to the dramatic population fall over the last 45 years from its peak of 247,000 in 1927 to about 130,000 in 1972. If a realistic denominator could be used the rate for 15 years or more would be substantially reduced, though Camberwell, too, has had a large decline in population. A similar adjustment, however, would also reduce the figure for 2-15 years which is already very much smaller than in other areas. Only the shortest period of stay, also relatively small in number, relates to the present population. These figures suggest that fewer people have been retained for long periods in Salford compared to the other areas in the 15 years before each census. But since the other censuses are from 7-13 years ago the foregoing 15 years for each of them represents almost a different era in psychiatric practice. We would expect comparative figures for 1 January 1972 to show a very different picture.

\section{LONG-STAY POPULATION}

The percentage breakdown by length of stay of long-stay patients at the 1968 and 1972 censuses is shown in tables $V$ and VI. There has been no change in the $15 \%$ of patients resident for less than five years (table VI). Successive censuses from 1968 
TABLE vI-Length of Stay of Salford (1968 and 1972 Censuses) Long-stay Patients Expressed as Percentage of Patients

\begin{tabular}{|c|c|c|c|c|c|c|}
\hline & & & & & & \\
\hline & & iear & & & 1 January 1968 & 1 January 1972 \\
\hline $\begin{array}{c}1-4 \\
5-9 \\
10-14 \\
15-19 \\
20-24 \\
25-29 \\
30-34 \\
35-39 \\
40-44 \\
45-49 \\
50+\end{array}$ & $\begin{array}{l}\because \\
\because \\
\therefore \\
\therefore \\
\therefore \\
\therefore\end{array}$ & $\begin{array}{l}\because \\
\because \\
\therefore \\
\therefore \\
\therefore \\
\therefore \\
\therefore\end{array}$ & $\begin{array}{l}\because \\
\because \\
\because \\
\because \\
\therefore \\
\because \\
\therefore\end{array}$ & $\begin{array}{l}\because \\
\because \\
\because \\
\because \\
\because \\
\because \\
.\end{array}$ & $\begin{array}{r}15.4 \\
11.6 \\
9.1 \\
13.7 \\
11.6 \\
14.0 \\
8.2 \\
7.5 \\
5.3 \\
2.2 \\
1.4\end{array}$ & $\begin{array}{r}15 \cdot 4 \\
7.5 \\
8 \cdot 6 \\
8.3 \\
13.5 \\
12.0 \\
12.9 \\
8.6 \\
6.9 \\
4.3 \\
2.0\end{array}$ \\
\hline
\end{tabular}

to 1972 show progressive increases in the proportion resident for longer periods, but table VI identifies these increases in the percentage resident 20 years or more. Between five and 19 years the percentage diminished, especially for patients resident 1519 years. This pattern suggests that fewer patients were retained for long periods in the late 1950s and early 1960s, but that this reduction has been less pronounced since. This is consistent with the view that around the time of the Royal Commission and the Mental Health Act, 1959, there was a wave of discharges from psychiatric hospitals mostly affecting not very long-stay patients who were easier to discharge, and which could not be sustained for more difficult patients later on.

The problem for the hospitals-and patients-is clear. At 1 January $196850 \%$ (209) of long-stay patients had been resident for 20 years or more; $25 \%$ (104) for 30 years or more. At the 1972 census the respective figures were $60 \%$ (209 patients) and $35 \%$ (122 patients). The longer a person remains in hospital the lower his chance of discharge, but the higher his chance of dying. While the total of long-stay patients is decreasing, in the longest-stay groups more new patients are accumulating than are being lost by death or discharge. A similar situation in Oxford is suggested by Baldwin (1972). The very low death rate of elderly patients without senile dementia is discussed below.

The change in the total long-stay population may be said to have two components. At the initial census long-stay patients constitute an "old long-stay" cohort which diminishes by discharge and death in subsequent years. At the same time, from each year's admissions, some patients remain at least a year and build up a body of "new long-stay" patients (table VII).

\section{DIMINUTION OF THE "OLD LONG-STAY" COHORT}

The decline in the total long-stay population is similar to previous studies in England and Wales (using two year's residence for comparison), being $26.1 \%$ in four years. Tooth and Brooke (1961) found $25.4 \%$ for England and Wales from a census at 31 December 1954, Hassall et al. (1965) found $26 \cdot 7 \%$ at Powick Hospital, Worcester, from 31 December 1957, and the Camberwell register's initial census population at 31 December 1964 reduced by $29.9 \%$ by the same day in 1968 (Hailey, 1971).
TABLE VIII-Salford Long-stay (one year or more) Inpatients at 1 fanuary 1968. Diminution over Four Years by Age and Sex and by Sex and Diagnosis (Figures are Percentages Adjusted for Ageing)

\begin{tabular}{|c|c|c|c|c|c|c|}
\hline \multirow[b]{3}{*}{$\begin{array}{l}\text { Age: } \\
\text { Under } 45 \text { years } \\
45-64 \text { years } \\
65 \text { years and over }\end{array}$} & & & & \multicolumn{3}{|c|}{$\begin{array}{l}\text { Percentage Decline } \\
1 \text { January 1968-72 }\end{array}$} \\
\hline & & & & M. & F. & Total \\
\hline & $\begin{array}{l}\cdots \\
\because \\
.\end{array}$ & $\begin{array}{l}\cdots \\
\ldots\end{array}$ & $\begin{array}{l}\cdots \\
\cdots\end{array}$ & $\begin{array}{l}54 \\
21 \\
24\end{array}$ & $\begin{array}{l}59 \\
34 \\
20\end{array}$ & $\begin{array}{l}55 \\
27 \\
21\end{array}$ \\
\hline \multicolumn{2}{|l|}{ Total all ages } & .. & .. & 30 & 29 & 29 \\
\hline \multicolumn{3}{|c|}{ 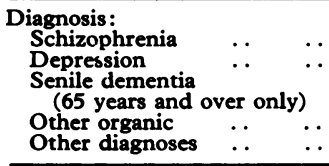 } & $\begin{array}{l}\cdots \\
\cdots \\
\cdots\end{array}$ & $\begin{array}{r}26 \\
44 \\
100 \\
23 \\
37\end{array}$ & $\begin{array}{l}17 \\
39 \\
65 \\
27 \\
23\end{array}$ & $\begin{array}{l}70 \\
25 \\
29\end{array}$ \\
\hline \multicolumn{2}{|c|}{ Total all diagnoses } & .. & .. & 30 & 29 & 29 \\
\hline
\end{tabular}

Only three patients at 1 January 1968 were under 25 years.

It is interesting that the same rate of decline persisted from 1954 to 1968. Salford does not show the excess decline among women that was found in Camberwell.

The percentage diminution by sex and age and by sex and diagnosis of the long-stay population over four years is given in table VIII. The number of young patients (less than 45 years) has declined much more rapidly than others. Among the middle aged (45-64 years) the number of women has declined more than men. The slowest decline is seen among the elderly (65 and over), being only $24 \%$ for men and $20 \%$ for women. This contrasts with the Camberwell study where a $41 \%$ and $48 \%$ decline, respectively, was shown for this age group from 31 December 1964 to 1968.

However, those patients aged 65 and over with a diagnosis of senile dementia showed an extreme decline of $65 \%$ for women and $100 \%$ for the very few men. Thus the group of elderly patients with a diagnosis other than dementia diminish extremely slowly $-14 \%$ for men and an increase of one patient for women, a mean diminution of only $5 \%$ in four years. Even if we were to assume that the reduction is entirely due to death, the death rate would be extremely low. This is not a small number of patients, 122 in 1968 and 116 in 1972 . The rate of decline of numbers in this group is depressed by the ageing of the population and consequent transfer of a number of patients previously in the 45-64 age group. In only four years, however, the effect of this is small. Apart from senile dementia and taking all ages together, patients with depression show the greatest decrease and those with schizophrenia the least.

\section{ACCUMULATION OF NEW LONG-STAY PATIENTS}

Of all admissions from Salford 5\% currently lead to a stay of one year or more, but the number of patients becoming longstay is not necessarily dependent on the number of admissions. It might be argued that potential long-stay patients, having the

TABLE VII-Salford Long-stay Inpatients, Diminution and Accumulation for the Years 1968-72, by Sex

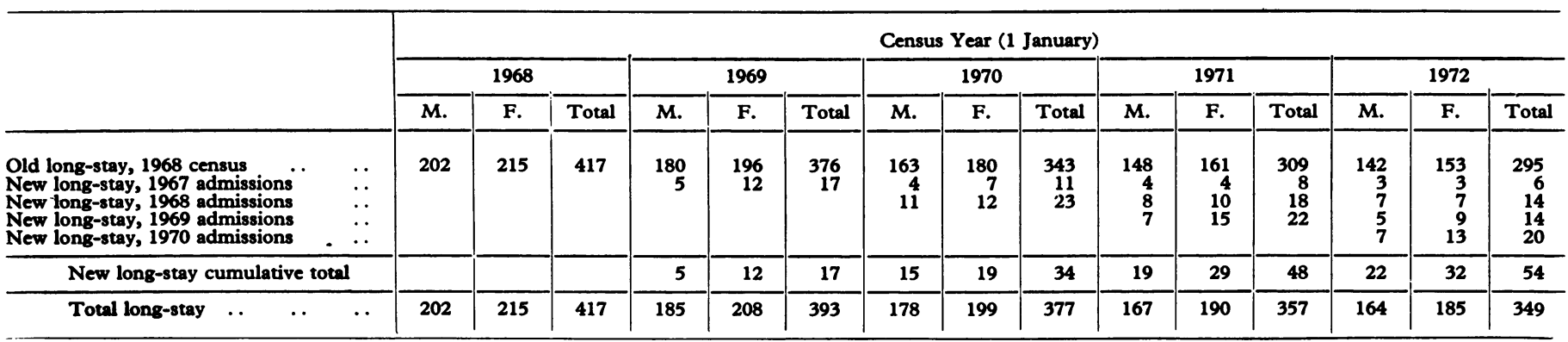


TABLE IX-Salford Inpatients at 1 fanuary 1972. Four Years' Accumulated Totals of New Long-stay Patients by Age, Sex, and Diagnosis

\begin{tabular}{|c|c|c|c|c|c|c|c|c|c|c|c|c|c|c|c|c|c|}
\hline & & & & \multirow{2}{*}{\multicolumn{2}{|c|}{ Age: }} & \multicolumn{4}{|c|}{ Male } & \multicolumn{4}{|c|}{ Female } & \multicolumn{4}{|c|}{ All Patients } \\
\hline & & & & & & $<45$ & $45-64$ & $65+$ & Total & $<45$ & $45-64$ & $65+$ & Total & $<45$ & $45-64$ & $65+$ & Total \\
\hline $\begin{array}{l}\text { Schizophrenia } \quad \ldots \\
\text { Depression } \\
\text { Organic psychoses } \\
\text { Other diagnoses }\end{array}$ & $\begin{array}{l}\ldots \\
\cdots \\
\cdots\end{array}$ & $\begin{array}{l}\ldots \\
\cdots \\
\cdots\end{array}$ & $\begin{array}{l}. \\
\because \\
\cdots\end{array}$ & $\begin{array}{l}\ldots \\
\because \\
\cdots\end{array}$ & $\begin{array}{l}\cdots \\
\cdots \\
\cdots\end{array}$ & $\begin{array}{l}8 \\
0 \\
0 \\
2\end{array}$ & $\begin{array}{l}4 \\
0 \\
3 \\
2\end{array}$ & $\begin{array}{l}0 \\
0 \\
3 \\
0\end{array}$ & $\begin{array}{r}12 \\
0 \\
6 \\
4\end{array}$ & $\begin{array}{l}4 \\
1 \\
1 \\
1\end{array}$ & $\begin{array}{l}7 \\
1 \\
0 \\
2\end{array}$ & $\begin{array}{r}2 \\
11 \\
1\end{array}$ & $\begin{array}{r}13 \\
3 \\
12 \\
4\end{array}$ & $\begin{array}{r}12 \\
1 \\
1 \\
3\end{array}$ & $\begin{array}{r}11 \\
1 \\
3 \\
4\end{array}$ & $\begin{array}{r}2 \\
1 \\
14 \\
1\end{array}$ & $\begin{array}{r}25 \\
3 \\
18 \\
8\end{array}$ \\
\hline Total & & & & & & 10 & 9 & 3 & 22 & 7 & 10 & 15 & 32 & 17 & 19 & 18 & 54 \\
\hline Senile dementia & . & . & . & . & . & - & - & 2 & 2 & - & - & 10 & 10 & - & - & 12 & 12 \\
\hline
\end{tabular}

most severe and least treatable illnesses or the least accommodating social situations, are all already admitted and would be admitted even if no other patients were.

The accumulated totals over four years, at the 1972 census, by sex, age, and diagnosis are shown in table IX. Of 54 patients two-thirds were women, predominantly with schizophrenia below 65 years and dementia 65 years and over. More than half the men had schizophrenia and were under 65 years, eight of the 12 being under 45 years. The three age groups were roughly equal, but below 45 years men predominated and at 65 years and over women outnumbered men by 6 to 1 . Of the 65 and over group two-thirds had senile dementia, but this remains a relatively small contribution to the accumulated total. Only three patients, all women, had a diagnosis of depression, though 21 short-stay and medium-stay patients at the 1972 census had this diagnosis, a quarter of the total. The number of schizophrenic patients accumulated in only four years is similar to the number of short-stay and medium-stay patients with schizophrenia at 1 January 1972. The same is true for the organic psychoses.

Age-specific rates of accumulation in four years, using the mean population for the period, were $0.33 / 1,000$ for those under 45 years, $0 \cdot 54 / 1,000$ for those between 45 and 64 , and $1 \cdot 17 / 1,000$ for those 65 and over. If we incorporate patients staying 1 year to less than 2 years from the 1968 census we can use a five-year period of accumulation. The corresponding age-specific rates were $0.36 / 1,000$ under $45,0.59 / 1,000$ for those between 45 and 54 , and $1 \cdot 35 / 1,000$ for those aged 65 and over. The accumulation of new long-stay patients and its contribution to future demand for beds is discussed elsewhere (Fryers, 1973). Such figures do not necessarily apply to other areas where psychiatric policies and practices differ from Salford's.

\section{Discussion}

The hope of a rapid reduction in the population of our large psychiatric hospitals has not been fulfilled. The expansion of general hospital psychiatric units has affected only short-stay and medium-stay patients and may, indeed, have helped to withdraw "active" psychiatric interest from the large institutions and their long-stay populations. Similarly, increased psychiatric and social work activity in the community during the last decade barely affected the people who had already been resident in hospital for some years.

In Salford comprehensive professional mental health social work flourished through the 1960 s in close co-ordination with active general and psychiatric hospitals (Freeman and Mountney, 1967). The justification for such a service rests primarily on the more careful, more humane, and more comprehensive help given to people normally domiciled in the community. There is little evidence that it has in any way minimized the use of hospital beds. Short-stay and medium-stay beds (under one year) in Salford have stood at about $60 / 100,000$ total population from 1968 to 1972 , and for under two years' residence at about $80 / 100,000$. This is not very much less than most others, from 1958 to 1964, shown in table IV.
The outstanding feature of the long-stay population (one year and more) in Salford is the large numbers that persist-349 people at 1 January 1972. Though great reduction may have taken place in the late 1950s and early 1960s since then it has been very slow, and in the period of four years studied the total fell by only $16 \%$. At the same time the proportion resident for very long periods increased. In 1972 over 200 people from Salford had been resident in psychiatric hospitals for 20 years or more, and over 120 for at least 30 years.

The decline of the "old long-stay" cohort is equally discouraging. Its overall effect is to leave us increasingly with old people without organic dementia and with a very low death rate and schizophrenic patients, many of whom have not yet reached 65 . These people, who have spent a very significant proportion of their lives in the psychiatric hospital, will not easily be rehabilitated into the ordinary community. Relatively few families are likely to persist with their care, and many homes in Salford have long been demolished. Alternative residential care facilities in appreciable numbers are as yet only plans. Hostels, group homes, and lodgings will have important parts to play, but for disabled, ageing, institutionalized hospital residents the advantage to the patient is not always obvious if compared with improved hospital accommodation. These very long-stay patients constitute a large body of disabled people who will be requiring our care and support, however and wherever delivered, for very many years yet.

This, of course, is no excuse for inaction. We desperately need to look beyond the figures, which show the problem in only the crudest way. We must make every effort to find out the needs and desires of each person concerned in some detail and with some care. Perhaps many would not now wish to leave the hospital which has been their home for so long. But there will be those, perhaps many, who would readily live with greater freedom and less support. There will be those for whom the various alternatives are entirely appropriate, but we cannot know and therefore cannot plan rationally unless we find out.

This assessment over whatever period is necessary would be best carried out jointly by experienced social workers from social services and an experienced doctor from the hospital. This need not hinder initial planning since the numbers are so large and provision of new facilities takes so long. But it gives us a chance at least to give a fair deal to people who have suffered much and have been mostly forgotten.

The extensive community mental health service has not prevented additions to the long-stay population, and the current accumulations of long-stay patients similarly needs further investigation. The impression of clinicians that people remain only rarely is to some extent true, though $5 \%$ of admissions is not exactly rare, but it needs only a handful of patients from each consultant each year. In Salford 54 people in only four years is not a small number, and they are mostly under 65 years old.

Why are they being admitted and retained? We need to examine each case closely to find the interplay between medical history, clinical state, social situation, service failure, and other factors. Perhaps it is these people who most need alternative forms of care when they are beginning their career as long-stay inpatients. 


\section{Conclusion}

From the figures alone we cannot be encouraged in the hope that the large psychiatric hospitals will readily be emptied of their long-stay populations, by whatever means. In Salford, at least, it is a population ever longer-staying, not by any means all old, increasingly difficult to discharge, and dying only slowly. And we replenish it year by year with new patients. We must examine the people concerned to discover what the "need" really is and to make rational provision, but the hospital and social services must work closely together to achieve this.

A further paper uses these and other data to estimate future demand for beds (Fryers, 1973).

This work is supported by a grant from the Department of Health and Social Security. Thanks are due to Miss K. Holt and the staff of the Salford register, to colleagues in the Manchester University Department of Social and Preventive Medicine, and at the Camberwell register.

\section{References}

Adelstein, A. M., Downham, D. Y., Stein, Z., and Susser, M. W. (1968). Social Psychiatry, 3, 47.
Baldwin, J. A. (1968). Health Bulletin (Edinburgh), No. 26.

Baldwin, J. A. (1967). British fournal of Preventive and Social Medicine, 21, 56.

Baldwin, J. A. (1972). Patients Resident in Psychiatric Hospitals in the Oxford Region 1970-1971. Research report No. 2. Oxford Regional Hospital Board.

Brooke, E. M. (1967). Ministry of Health Reports on Public Health and Medical Subjects, No. 116. London, H.M.S.O.

Brown, G. (1960). Acta Psychiatrica Scandinavica, 35, 414

Cross, K. W., and Yates, J. (1961). Lancet, 1, 989.

Freeman, H. L., and Mountney, G. H. (1967). In New Aspects of Mental Health, ed. H. Freeman and J. Farndale. London, Pergamon.

Fryers, T. (1973). Psychiatric In-patients from an Urban Community, 19681972. The Demand for Beds: Estimates for 1982. In preparation.

Fryers, T., Freeman, H. L., and Mountney, G. H. (1970). Social Psychiatry, $5,187$.

Gore, C. P., Jones, K., Taylor, W., and Ward, B. (1964). Lancet, 1, 457.

Hailey, Anthea M. (1971). Psychological Medicine, 1, 128.

Hassall, C., Spencer, A. M., and Cross, K. W. (1965). British fournal of Psychiatry, 111, 420.

Shepherd, M. (1957). A Study of the Major Psychoses in an English County. London, Chapman and Hall.

Susser, M. W., Stein, Z., Mountney, G. H., and Freeman, H. L. (1970). Social Psychiatry. 5, 69.

Tooth, G. C., and Brooke, E. M. (1961). Lancet, 1, 710.
Wing, L., Bramley, C., Hailey, A., and Wing, J. K. (1968). Social Psychiatry, , L., Bram

Wing, J. K., and Hailey, A. M. (1972). Evaluating a Community Psychiatric Service. London, Oxford University Press.

\section{Placental Lactogen Levels in Diabetic Pregnancy}

\section{W. URSELL， M. BRUDENELL， T. CHARD}

British Medical fournal, 1973, 2, 80-82

\section{Summary}

A prospective study has been carried out of placental lactogen levels in pregnancy complicated by diabetes mellitus. The levels were higher than those in normal pregnant subjects; the higher levels were related to increased placental and fetal weight but more closely to the former; and lower levels were found when there was clinical evidence of placental dysfunction. Those patients requiring the largest insulin increment for the control of their diabetes in the pregnancy have placental lactogen levels in the higher range.

\section{Introduction}

The chemical and biological similarity between human placental lactogen (HPL) and human growth hormone suggests that it plays a part in the altered carbohydrate metabolism of pregnancy (Grumbach et al., 1966; Beck and Daughaday, 1967; Samaan et al., 1968; Kalkhoff, 1969). It may also be a useful diagnostic marker for fetal well-being in pregnancies complicated by diabetes mellitus (see table). The present study, which is based on a large number of samples from 34 consecutive pregnant diabetic patients, was designed to assess the relation of HPL levels to insulin requirements during pregnancy, and to define further its place as an index of fetal risk in diabetic pregnancies.

\footnotetext{
Department of Obstetrics and Gynaecology, King's College Hospital, London S.E.5

W. URSELL, F.R.C.s., M.R.C.o.G., Senior Registrar (Present appointment, Consultant, South-East Kent Group of Hospitals)

M. BRUDENELL, F.R.C.S., M.R.C.O.G., Consultant

Department of Obstetrics and Gynaecology, St. Bartholomew's Hospital, London EC1A $7 \mathrm{BE}$

T. CHARD, M.D., M.R.C.o.G., Senior Lecturer
}

\section{Subjects, Materials, and Methods}

A total of 219 measurements were carried out in 34 patients with abnormal glucose tolerance tests during pregnancy. Twentynine patients received insulin, three of these becoming insulin dependent only during the pregnancy. Sixteen of the patients were primiparous and there was one set of twins. There was no maternal or perinatal mortality. Diabetic control was achieved as described by Brudenell and Beard, 1972.

Infant weight at delivery was expressed as a percentile above or below the normal mean corrected for gestational age, sex, and parity, and placental weight as the number of grammes above or below the normal mean after correction for gestational age.

Insulin increment was calculated as the percentage increase in the dose at delivery over that required at 20 weeks. Thirteen patients had increments above $100 \%$ and 13 patients increments below $100 \%$.

A group of 11 patients with evidence of placental dysfunction in addition to diabetes was distinguished. This included four cases of pre-eclamptic toxaemia, seven with infants whose birth weight was below the 25 th percentile for their period of gestation, and three in which fetal distress, confirmed by cardiotochometry and $\mathrm{pH}$ estimations, occurred in labour.

Blood samples were collected at each antenatal visft from 20 weeks' gestation onwards, and weekly during routine admission from 32 weeks until delivery. Specimens were collected between 11 a.m. and noon, and plasma HPL levels measured using a semiautomated radioimmunoassay (Letchworth et al., 1971). All results were analysed after logarithmic transformation, and the significance of differences between means assessed by Student's $t$ test.

\section{Results}

For the whole group mean HPL levels were above those of the normal population after the 28 th week (fig. 1). The levels were related to both placental and fetal weight $(P<0.001$ and $<0.05)$. The levels were lower in those subjects with placental dysfunction than those without $(P<0.001)$ (fig. 2). In the former 